\title{
Discussion at Chicago Convention
}

\section{CONTINUED DISCUSSION OF "MAGNETIC FLUX DISTRIBUTION IN TRANSFORMERS" (Mc EACHRON).} Chicago, Ill., April 19, 1922. See October Journal, page 757.

Alfred Still: In order to avoid the confusion of ideas which is likely to arise when the various components of the total flux are represented as occupying the same portion of the iron core, the vector diagram for a loaded transformer may be drawn as in Fig. 1.

Owing to magnetic leakage, the flux will not be the same at all sections of the iron core, and it is not possible to represent correctly the flux conditions in the transformer without abandoning the idea of each unit line or tube of induction being closed upon

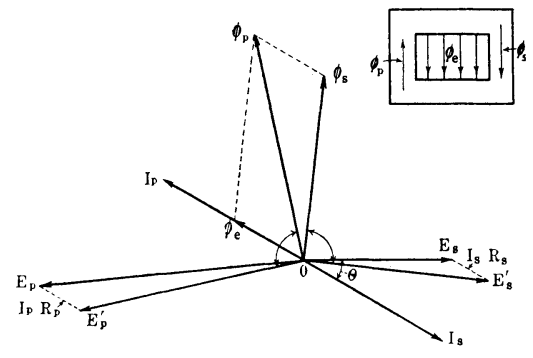

Fig. 1

itself. In the sketch of the simple transformer shown in Fig. 1, the lines marked $\Phi_{l}$ represent the leakage flux while $\Phi_{p}$ and $\Phi_{s}$ stand for the fluxes which link with the primary and secondary windings respectively. The arrow-points indicate what will be considered the positive direction of these fluxes. It is then always true that the flux $\Phi_{p}$ is equal to the (vectorial) addition of the fluxes $\Phi_{s}$ and $\Phi_{l}$, or

$$
\Phi_{p}=\Phi_{s}+\Phi_{l}
$$

On the assumption that the magnetizing component of the current is negligible and that the winding ratio is 1 to 1 , the vector diagram may be constructed as follows:

Draw $O E_{s}$ and $O I_{s}$ to represent the (known) secondary terminal voltage and current with the angle $\theta$ between them corresponding to a load power factor of $\cos \theta$. The other vectors are drawn in the following order
$E_{s} E_{s}{ }^{\prime}$, parallel to $O I_{s}$ and of the proper length to represent the ohmic drop of $I_{s} R_{s}$ volts in the secondary windings.

$O E_{s}{ }^{\prime}$, the e. m. f. which must be induced in the secondary windings.

$O \Phi_{s}$, drawn $90 \mathrm{deg}$. in advance of $E_{s}{ }^{\prime}$, is the flux which links with the secondary windings.

$O I_{p}$, equal and opposite to $I_{s}$, is the primary current.

$O \Phi_{l}$, in phase with $I_{p}$ is the leakage flux.

$O \Phi_{p}$, the resultant obtained by the vectorial addition of $\Phi_{s}$ and $\Phi_{l}$ is the flux which links with the primary windings.

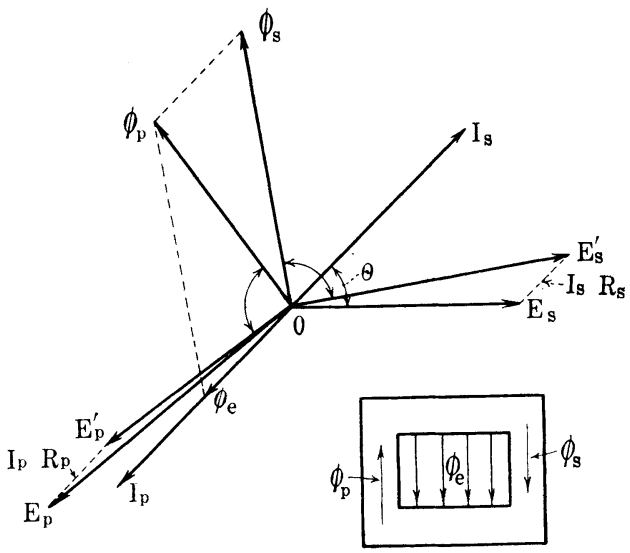

FIG. 2

$O E_{p}{ }^{\prime}$, drawn $90 \mathrm{deg}$. in advance of $\Phi_{p}$, is the component of the impressed primary e.m.f. necessary to balance the e.m.f. induced in the primary windings by the flux $\Phi_{p}$.

$E_{p}{ }^{\prime} E_{p}$, parallel to $I_{p}$ and of the proper length to represent to ohmic drop of $I_{p} R_{p}$, volts in the primary windings.

$O E_{p}$, the voltage which must be impressed at primary terminals to produce the secondary load conditions which have been assumed.

In Fig. 2, exactly the same procedure has been followed in drawing the vector diagram for a transformer with a capacity loaid.

\section{Discussion at Annual Convention}

\section{THE ECONOMICS OF D-C. RAILWAY DISTRIBUTION WITH PARTICULAR REFERENCE TO THE AUTO- MATIC SUBSTATION*}

(Crecelius and Phillips), Niagara Falls, Ontario, June 27, 1922

V. E. Thelin: The manually operated substations now in operation on railway systems in large cities offer a wonderful field for the use of automatic equipment, due to the fact that the line losses can be reduced considerably, schedule speeds increased, and in many cases sufficient copper can be taken down to pay for the cost of the land and new buildings as well as that of moving the machines. If the manually operated substations, which have a capacity of from 4000 to $20,000 \mathrm{kw}$., are redistributed into any number of single-unit or, at the most, two-unit automatically controlled substations, the service rendered by same no doubt will be far superior to that now obtained in the manually operated substations, due to the fact that each operation in the automatic substation has been worked out beforehand and the entire sequence is carried through without any hesitancy or error such as frequently happens to the operator in manually

*A. I. E. E. Journal, 1922, Vol. XLI, May, p. 363. controlled stations. In the large manually operated substations with many units it is necessary to clear the board of practically all the feeder sections before the first rotary can be connected to the bus, whereas a single-unit automatic substation will have a maximum of say from five to eight feeders, and there should be no difficulty experienced in the station picking up all the sections simultaneously. It is possible, through the use of special devices which I have in mind, to isolate each substation district from all other districts, and by using automatic reclosing circuit breakers service can be restored quickly, whereas if all substations were tied together through bus lines the first station to be connected to the system would open up an overload through excess of load fed from the surrounding substation districts through the bus lines.

It seems, for many reasons, that the ideal automatic substation layout in a large metropolitan eity is the single-unit substation layout. A two-unit substation requires the use of high-tension line oil switches, rotary oil switches and transfer switches, together with the expensive bus bar compartment construction for line busses, transfer busses and rotary busses, and where compound rotaries are used equalizer busses must be used, and the automatic control for a multiple-unit substation becomes very 